\title{
Berkeley: sobre el conocimiento nocional de la mente
}

\section{Berkeley: On Notional Knowledge of Mind}

\author{
ALBERTO LUIS LÓPEZ \\ Université du Québec à Trois Rivières (Canadá)
}

Recibido: 17/02/2016 Aceptado:06/10/2016

\section{RESUMEN}

En este artículo expongo y analizo la propuesta berkeleyana del conocimiento nocional, que representa entre otras cosas el intento del irlandés por conocer a la mente o espíritu, esto es, a aquella cosa pensante y activa que por su propia actividad resulta irrepresentable como idea. Como el conocimiento nocional ya se menciona en los Comentarios Filosóficos me remitiré a ellos para conocer los orígenes del mismo; sin embargo, como tal conocimiento aparece con mayor detalle en obras posteriores me serviré sobre todo del Tratado para abordar la compleja doctrina nocional.

\section{PALABRAS CLAVE}

NOCIÓN, MENTE, IDEA, LENGUAJE, INMATERIALISMO

\begin{abstract}
In this paper I expose and analyze the berkeleian proposal of notional knowledge. Among other things, this proposal represents Berkeley's attempt to know the mind or spirit, that is, the thinking and active thing that, by its own activity, results unrepresentable as idea. As such knowledge is already mentioned in the Philosophical Commentaries I will refer to them to know the origins of that proposal. However, as notional knowledge appears in more detail in later works I will make use especially the Treatise to tackle the complex notional doctrine.
\end{abstract}

KEY WORDS

NOTION, MIND, IDEA, LANGUAGE, IMMATERIALISM

(C) Contrastes. Revista Internacional de Filosofía, vol. XXII-Nº1 (2017), pp. 137-154. ISSN: 1136-4076

Departamento de Filosofía, Universidad de Málaga, Facultad de Filosofía y Letras Campus de Teatinos, E-29071 Málaga (España) 


\section{INTRODUCCIÓN}

Dentro de la FILOSOFÍA DE Berkeley sobresalen los dos elementos que conforman su ontología y que generaron extrañeza y críticas en algunos de sus lectores: las ideas y los espíritus o mentes. Por diversos motivos las ideas fueron el principal causante de las malas lecturas e interpretaciones de su inmaterialismo, mientras que, por el contrario, el elemento espíritu no resultó tan ajeno a la tradición y por consiguiente no fue tan cuestionado por los lectores de sus obras. En relación al espíritu hay un tema que destaca y que se origina, de hecho, a partir del propio término espíritu, pues cuando uno piensa en él viene a la mente del lector una primera pregunta que interroga por el qué, es decir, qué es eso llamado espíritu o mente (cuestión que abordaré en la primera parte del trabajo). Esta primera pregunta viene acompañada usualmente de una segunda que se sigue naturalmente de ella, pero que ya no interroga por el qué sino por el cómo, esto es, cómo se conoce al espíritu. Intentar responder esta última pregunta es el objetivo de este escrito y para ello será necesario recurrir al conocimiento nocional, también conocido como doctrina de la noción. Dicho conocimiento - por cierto- no es más que una consecuencia del inmaterialismo berkeleyano, pues al postular éste una entidad como el espíritu era de esperarse que fuese posible acceder a él, ya que de lo contrario, es decir, de no poder conocerlo, el inmaterialismo resultaría contradictorio porque llevaría al escepticismo, cuya superación era uno de los propósitos centrales de Berkeley. ${ }^{1}$

El conocimiento nocional, es necesario decir, fue planteado por el irlandés para acceder epistémicamente a cuatro elementos de su filosofía, a saber, nuestra propia mente (o espíritu), las otras mentes, Dios y las relaciones. ${ }^{2}$ Por una cuestión de unificación temática me centraré solamente en los dos primeros elementos, esto es, en mi mente o yo y en las otras mentes o yoes, porque ambos se enfocan en una misma cuestión, más específica, que es la mente o espíritu (finito).

Para explicar entonces la propuesta sobre el conocimiento de la mente, la propia o las otras, habrá que decir primero qué es para Berkeley la mente. Luego será conveniente acercarse a los Comentarios Filosóficos ${ }^{3}$ para conocer

1 Basta con leer el título completo del Tratado y de los Tres Diálogos para confirmar esto.

2 Principios, II, $\S \S 89$ y 142, 79-80 y 106 respectivamente. Las referencias a las obras de Berkeley se toman de la edición de Luce y Jessop: Berkeley 1948-57. Citaré en el orden tradicional: nombre de la obra en inglés, volumen en números romanos, sección (§) y página.

3 Para los Comentarios Filosóficos usaré la traducción de Robles de 1989. Me referiré a los Comentarios Filosóficos como Comentarios o $C F$, al Tratado sobre los principios del conocimiento humano como Tratado o Principios y a los Tres Diálogos entre Hilas y Filonús como Diálogos. Cuando hablo de la obra no publicada me refiero específicamente a los $C F$, pu- 
cómo se fue configurando la doctrina nocional en esa obra no publicada; esto servirá para poder explicar de mejor manera el conocimiento nocional en su versión definitiva. Conviene señalar - para el lector no avezado en temas berkeleyanos- que la cuestión de cómo conocer la mente o espíritu no fue desarrollada plenamente por Berkeley. Si bien en sus obras se encuentran referencias o comentarios sueltos sobre el asunto, que permiten colegir el profundo interés que el tema suscitó en él, no hay como tal una elaboración sistemática ni completa en sus escritos, lo que evidentemente resulta una limitante para los estudiosos; pese a ello intentaré explicar y analizar aquí la interesante y compleja propuesta sobre el conocimiento nocional o, dicho en otras palabras, sobre la manera en que se puede conocer a la mente o espíritu.

\section{II. ¿QUÉ ES LA MENTE PARA BERKELEY?}

Antes de hablar sobre el conocimiento nocional es necesario remitirse a la mente o espíritu berkeleyano y con él, aunque sea brevemente, a las ideas. Esto es importante por lo que señala el propio irlandés, a saber, porque el «conocimiento humano puede reducirse naturalmente a dos clases, de las ideas y de los espíritus» ${ }^{4}$ siendo ambas clases -afirma- «totalmente distintas y heterogéneas y no tienen nada en común salvo el nombre» [de cosa o ser]. ${ }^{5}$

Como se sabe, para Berkeley existen dos tipos de ideas: 1) las del sentido y 2) las de la memoria y la imaginación (también denominadas ideas «de la reflexión» $[\S 25])^{6}$. Las dos ideas existen igualmente en la mente (en tanto que ésta las percibe y con ello les da existencia) aunque son distintas de ella, entre otras cosas porque las primeras son impresas en los sentidos, por eso les llama «cosas reales», mientras que las segundas son generadas por la propia mente, por ello las denomina "propiamente ideas o imágenes de cosas». ${ }^{7} \mathrm{~A}$ pesar de ser dos tipos de ideas ambas tienen algo en común que las asemeja ontológicamente, a saber, su pasividad, de ahí que Berkeley sostenga en sus Principios que «el verdadero ser de una idea implica pasividad e inercia en

blicados hasta el siglo XIX, mientras que por obra publicada hago referencia al resto de escritos publicados por Berkeley.

4 Principles, II, § 86, p. 78.

5 Ibid., $\S 89$, p. 79.

6 En Principios $\S 1$ Berkeley menciona que los objetos del conocimiento humano son tres: «o ideas actualmente impresas en los sentidos, o bien los percibidos atendiendo a las pasiones y operaciones de la mente, o finalmente ideas formadas con ayuda de la imaginación y la memoria». Pese a que el siglo pasado hubo algunos debates sobre si las pasiones y operaciones de la mente eran o no ideas, en la actualidad hay bastante consenso al considerarlas algo distinto de las ideas. Al respecto, léase detenidamente Principios $§ 25$ y 27.

7 Ibid., $\S 33,54$. 
ella». ${ }^{8}$

La segunda clase de conocimiento humano -el realmente importante para este apartado- es la de los espíritus o mentes. Intentaré dar ahora, aunque sea sucintamente, una caracterización de las mentes lo menos «relativa» y lo más «positiva» posible. ${ }^{9}$ Las mentes, al igual que las ideas, fueron caracterizadas definitivamente en la obra publicada, es decir, en el Tratado (1710) y en los Diálogos (1713); sin embargo, como esta última obra es hasta cierto punto una iteración del Tratado, lo que no implica que no contenga información novedosa, complementaria y útil para mejor comprender los postulados inmaterialistas, me centraré principalmente en el escrito de $1710 .^{10}$

En el Tratado se concibe a la mente o espíritu como aquello que «conoce o percibe» ( $(2)$ las ideas u objetos del conocimiento, y que ejerce diversas operaciones sobre ellas como querer, imaginar o recordar, lo que lo convierte en un ser activo y perceptor ${ }^{11}$ denominado, indistintamente, «mente, espíritu , alma o yo mismo» (§2). Para Berkeley estos cuatro sinónimos no se refieren a una idea sino a algo totalmente distinto de ella, esto es, «en donde existen [las ideas] o, lo que es lo mismo, mediante lo cual son percibidas». ${ }^{12} \mathrm{El}$ espíritu o mente, en tanto ser activo ${ }^{13}$, tiene entonces la capacidad de percibir y con ello dotar de existencia a las ideas, pues (gracias a su percepción) puede poseerlas; que los espíritus o mentes doten de existencia ${ }^{14}$ al percibir resulta ser una

8 Ibidem, $\S 25$, p. 52.

9 Hablo de caracterización «positiva» y «relativa» (más precisa y menos precisa, respectivamente) retomando la idea de Flage de distinguir entre «nociones positivas y relativas». $C f$. Flage 1985, p. 408 ss. También me baso en lo que señala el propio Flage, respecto a que Berkeley llega a utilizar las palabras «noción» y «definición» como sinónimos. Véase Flage, op. cit., p. 411 y Dialogues, II, p. 233.

10 Sobre la conformación del espíritu en Berkeley, véase Robles 1984 y 1986, pp. 67-87 y pp. 43-54 respectivamente.

11 En los Diálogos también se reiteran estas características: «Ph. ¿Cuántas veces tengo que repetirte que conozco o soy consciente de mi propio ser, y que yo mismo no soy mis ideas sino algo más, un principio pensante y activo que percibe, conoce, quiere y actúa sobre las ideas?». Dialogues, II, p. 233.

12 Principles, II, § 2, p. 42.

13 Para Benítez decir que la mente es activa equivale a explicitar «sus principios de actividad, sus funciones y operaciones básicas». Los principios refieren a que «la acción de la mente se despliega a partir del principio activo de la voluntad y se remite a dos polos básicos [...]: el entendimiento que genera todas las operaciones intelectuales y la volición que genera todas nuestras pasiones, sentimientos, deseos, fantasías, etc.». Las funciones son «idear, sentir, querer, recordar, imaginar y percibir», mientras las operaciones básicas se reducen a pensar y percibir. Benítez 1986, pp. 27-28.

14 Herrera sostiene, hablando de la relación entre existencia y espíritu, que «existir es ser activo (o inactivo), pero que [sic] la acción puede ser de dos clases distintas, a saber, percepción, 
oración comprensible, empero, para aclarar aún más este enunciado conviene preguntarse a qué se refiere Berkeley con el término percibir. ${ }^{15}$

En $\S 4$ aparece parte de la respuesta a la anterior interrogante, cuando el filósofo se pregunte afirmando «¿Y qué percibimos además de nuestras propias ideas o sensaciones?». ${ }^{16}$ Se colige de la cita que con 'percibir' Berkeley se refiere tanto a la percepción sensible, que a través de los sentidos capta sensaciones, como a la percepción inteligible, que a través del intelecto capta ideas («pues tener una idea es lo mismo que percibir», ${ }^{17}$ señala en la misma obra). Por otro lado, gracias a que la percepción, al percibir, dota de existencia a lo sensible y a lo inteligible tiene sentido decir, respecto a lo primero, que «la mesa sobre la que escribo existe, es decir, la veo y la palpo; y si estuviera fuera de mi despacho diría que existe, queriendo dar a entender con ello que si estuviese en el despacho podría percibirla, o que algún otro espíritu la percibe actualmente» ${ }^{18} \mathrm{y}$, respecto a lo inteligible, que «imagino el tronco de un cuerpo humano sin sus miembros o concibo el olor de una rosa sin pensar en la rosa misma». ${ }^{19}$

Por otro lado, la percepción hace posible conocer, lo que a su vez reafirma la particularidad del espíritu como ser activo. A través de la percepción se conoce, por eso se puede afirmar que las cosas existen cuando son percibidas o conocidas, lo que implica que percibir es equiparable a conocer; sin embargo, este conocer conlleva implícitamente actuar porque sólo siendo activo se conoce y -cabe añadir- sólo en la actividad se percibe, de ahí que «actuar es o bien percibir o bien crear o inducir percepciones en otras mentes [de Dios a los hombres] o en nosotros mismos [mediante la imaginación]». ${ }^{20}$ Es precisamente el hecho de que la mente perciba, y mediante la percepción conozca y dote de existencia, lo que lleva a sostener que ninguno de los cuerpos que componen el mundo subsiste sin una mente, puesto que «su ser es ser percibidos o conocidos»; ${ }^{21}$ evidentemente esto se aplica tanto a las entidades

si proviene del entendimiento, o volición, si proviene de la voluntad» (p. 19). Concluye que la noción de existencia es ambigua y «multívoca» en Berkeley, pues «parece ser relacional o, en todo caso, una propiedad disyuntiva compleja». Herrera 1986, p. 22.

15 En Berkeley el término 'percibir' es polisémico y por ello bastante complejo; refiere a muchas acciones de la mente como concebir, considerar, imaginar, inducir, formar (causar), conocer o experimentar.

16 Principles, II, § 4, p. 42.

17 Ibid., § 7, p. 44.

18 Ibid., § 3, p. 42.

19 Ibid., § 5, p. 43.

20 Herrera, op. cit., p. 18.

21 Principles, II, § 6, p. 43. Con el «esse est percipi aut percipere» se establece el nuevo principio del inmaterialismo. 
extramentales, es decir, a cualquier objeto externo como sería la materia, ${ }^{22}$ como a las intramentales, el caso de las ideas o los números (que no son más que una «invención» de la mente por ser siempre relativos al entendimiento humano $[\S 12])$.

Una característica importante de la mente -ya señalada por Descarteses que «siempre piensa» ( $§ 98)$; precisamente el estar pensando y con ello percibiendo, conociendo y dotando de existencia hace que no se pueda separar «la existencia de un espíritu de su actividad pensante o cogitation». ${ }^{23}$ El pensar (término multívoco en Berkeley ${ }^{24}$ ) permite complementar la caracterización de la mente para entenderla como «aquello que piensa, quiere y percibe» ( $\S$ 38), es decir, como un «ser activo, cuya existencia no consiste en ser percibido sino en percibir ideas y en pensar». ${ }^{25}$ La combinación entre percibir ideas y pensar permite que la mente se percate de que el tiempo no es otra cosa que la «sucesión de ideas en nuestra mente» (§ 98), y a partir de esto reflexione sobre sí misma para darse cuenta de su propia finitud, esto es, de que «la duración de cualquier espíritu finito es estimada por el número de ideas o acciones que se suceden unas a otras en el mismo espíritu o mente». ${ }^{26}$

La mente, en tanto activa y perceptora, dota de existencia a las cosas o ideas porque éstas no pueden existir sin una mente que las perciba. Esta característica de ser soporte y receptáculo de percepciones es lo que la convierte en sustancia (término usado por Berkeley justamente como «soporte o sujeto» de ideas), e incluso en la única, pues «no existe ninguna otra sustancia más que el espíritu o aquello que percibe». ${ }^{27} \mathrm{El}$ que la mente o espíritu sea sustancia se demuestra porque todas las cosas, conformadas por la unión de cualidades primarias y secundarias, no son sino ideas percibidas por los sentidos, y lo percibido

22 Aunque la materia fuese concebida como algo extramental eso no implicaría -para Berkeley- que no fuese una idea en la mente, pues para existir tendría que ser percibida sensible o inteligiblemente; por ello si se le percibe y conoce es porque se trata de una idea en la mente: «Cuando nos esforzamos al máximo en concebir la existencia de cuerpos externos estamos contemplando sólo nuestras propias ideas» (este razonamiento se sigue de Principles $\S \S 18,19$ y 23). En Principles $\S 23$ y en el primero de los Diálogos aparece el llamado «Master Argument», considerado por Berkeley autosuficiente para establecer su «idealismo básico», esto es, «que los objetos cotidianos no pueden existir sin una mente que los perciba». Bettcher 2008, pp. 38-41 y 50-54.

23 Principles, II, § 98, p. 84.

24 Benítez sostiene que para Berkeley «pensar» tiene varios significados: a) es recibir percepciones o ideas sensibles, b) es destacar objetos, elaborar conceptos o inferir leyes, c) es formar a voluntad fantasías y recuerdos, y d) es tener nociones de sustancias activas, de operaciones, de relaciones. Benítez, op. cit., p. 28.

25 Principles, II, § 139, p. 105.

26 Ibid., § 98, p. 83.

27 Ibid., § 7, p. 43. 
sensiblemente, junto con lo percibido inteligiblemente, no puede existir más que en una mente perceptora; de ahí que la mente al ser la encargada de captar, mantener y dar existencia a lo percibido se convierta en su sostén y soporte, es decir, en una sustancia, lo que explica por qué Berkeley afirma que «un espíritu es la única sustancia o soporte en que los seres no pensantes o ideas pueden existir». ${ }^{28}$ Esta única sustancia, que convierte a la mente en un «agente subsistente por sí» ( $§ 137)$, no es corpórea ni material sino todo lo contrario, es «activa, simple y no compuesta» ( $\$ 141)$, «incorpórea» $(\S 26)$ e «indivisible» ( $(27)$ y por eso es mental o espiritual; precisamente este hecho es lo que permite denominarle, además de mente o espíritu, «alma humana» (§ 36) y equipararla por momentos con la voluntad. El propio Berkeley enriqueció su definición de mente al decir que se trata de «un ser simple, indivisible, activo: en tanto que percibe ideas se le denomina entendimiento y en tanto que las produce u opera sobre ellas se denomina voluntad». ${ }^{29}$ Esto significa que está integrada por dos operaciones, una receptora y otra actuante, cuyo objetivo es recibir las ideas del sentido y operar sobre las ideas de la reflexión, las cuales, gracias a la experiencia, resultan de asociar unas ideas con otras para formar nuevos conjuntos de ideas o cosas, dando paso con ello a las ideas de la memoria y la imaginación.

\section{LA PREFIGURACIÓN DEL CONOCIMIENTO NOCIONAL: LOS COMENTARIOS FILOSÓFICOS}

He dicho que la mente no es una idea porque al ser las ideas «inactivas» e «inertes» no pueden representar algo distinto de ellas mismas; por el contrario, la mente es caracterizada como una "cosa Activa», ${ }^{30}$ lo que trae como consecuencia que no haya semejanza alguna entre las dos entidades (mente e ideas) y que, por lo tanto, resulte imposible conocer a la mente como idea, entendida ésta -sobre todo en la etapa de los Comentarios-como imagen o representación intelectual de algo. Si sólo se conocen ideas pero a la mente no se le conoce a través de ellas vuelve entonces la pregunta que dio origen a este trabajo: ¿cómo se conoce a la mente?

Una primera aproximación puede hacerse a partir de los Comentarios Filosóficos (1707-1708), en donde Berkeley vislumbra lo que es la mente, pero también se muestra consciente de la dificultad que conlleva para el lenguaje explicar cómo se le conoce, pues al no ser una idea resulta difícil expresarla con palabras que, por lo general, expresan o remiten a ideas; por eso señala en

28 Ibid., § 135, p. 103. Para conocer algunos problemas interesantes que se desprenden de la sustancia espiritual véase Muehlmann 1995, pp. 89-105, y Robles 1990, pp. 101-130.

29 Principles, II, § 27, p. 52.

30 Así la define en varias notas de los Comentarios, véase $C F$ 286, 362a, 673 y 712. 
los Comentarios que «sabemos muchas cosas que no podemos expresar por falta de palabras»». ${ }^{31} \mathrm{El}$ reconocimiento de este problema, fundamental para el conocimiento de otras mentes, se ve con mayor claridad en la nota 178 , donde escribe:

La imposibilidad de definir o de discurrir claramente acerca de la mayoría de las cosas proviene de los defectos y la limitación del lenguaje, quizá en la misma medida que de la oscuridad y confusión del Pensamiento. Por lo tanto yo podría clara y plenamente entender mi propia Alma la extensión, etc jsin ser capaz de definirlas $!^{32}$

Entender algo sin ser capaz de definirlo, sea por la limitación o complejidad del lenguaje o porque no se trata de una idea como imagen, no es restrictivo de la mente sino que también se aplica, por ejemplo, a ciertas acciones o actos. Por eso afirma el filósofo irlandés que «Mo No tenemos Ideas de las virtudes y los vicios, ni Ideas de Acciones Morales [...] pues la moralidad consiste principalmente de la Volición». ${ }^{33}$ Sobre esta misma cuestión vuelve en otra nota: «E De esto estoy seguro no tengo ninguna idea tal de Existencia o anexa a la Palabra Existencia». A partir de estas dos citas podría uno preguntarse si el hecho de no tener idea de una virtud o de una acción implica que esa virtud o acción carezca de sentido, la respuesta para Berkeley es que no. Lo mismo ocurre entonces con la mente, de la que si bien no tenemos idea eso no implica que no resulte ser una palabra plenamente significativa. ${ }^{34}$

En los $C F$ se muestra un Berkeley consciente de la casi inefabilidad del término mente, lo que no le imposibilita comprender, quizá intuitivamente, a qué se refiere esa palabra; por eso sostiene que no es un escéptico respecto al conocimiento de la mente: «Yo estoy más alejado del Escepticismo que cualquier hombre. Conozco con un conocimiento intuitivo la existencia de otras cosas así como mi propia Alma. esto es lo que Locke ni escasamente cualquier

$31 C F$ 223, p. 42. Quizá la dificultad de expresar con palabras el conocimiento de los espíritus se debe a que cuando Berkeley pensó en esto, época de los $C F$, aún no se había desligado del todo de la tesis «semántico ideísta lockeana», pues al creer que toda palabra remitía a ideas, y la mente no ser una idea, se entiende porqué decidió servirse de la tesis nocional en vez de usar algún término ya establecido. $C f$. Locke 1979, libro II, pp. 104 ss y Robles 1990, p. 113 ss.

32 CF 178, p. 40. Véanse también las notas 209 y 636.

Nota aclaratoria: al inicio de cada comentario Berkeley escribió una letra o símbolo para clasificarlo según el tema, por eso muchas notas inician con «S» (Spirit, Soul), «E» (Existence), «X» (Mathematics), etc. Al citar los $C F$ incluyo la clasificación del propio autor.

33 CF 669, p. 101

34 Esta cuestión se relaciona con la teoría del lenguaje emotivo que Berkeley desarrolló sobre todo en el diálogo VII de Alcifrón, con el propósito de considerar y analizar aquellas palabras que son significativas pese a no producir ninguna idea en la mente. 
otro Filósofo Pensante aspira a tener». ${ }^{35}$ Esta cita evidencia que un primer acercamiento al conocimiento de la mente se da a través de una intuición, ya que uno sabe y entiende, sin necesidad de verbalizarlo, a qué se refieren palabras como «nosotros, nosotros mismos, nuestra mente»; ${ }^{36}$ sin embargo, esto no es suficiente para ser capaces de determinar de qué manera o cómo se le conoce, por ello Berkeley requerirá de algo más, como es el hecho de ser afectado por otras mentes a través de los pensamientos o, sobre todo, de las sensaciones: «S. No podemos Concebir otras Mentes además de las nuestras sino como otros tantos yoes. Nos suponemos nosotros mismos afectados con tales y cuales pensamientos y tales y cuales sensaciones». ${ }^{37}$

La afectación de la que habla lo llevará a barruntar el término noción, aunque debe aclararse que en los Comentarios el uso de tal término es más bien laxo, casi como sinónimo de intuición. Al respecto dirá en la nota 540: «x La vasta, Esparcida, Universal Causa de nuestros Errores. Es que no consideramos nuestras propias nociones, quiero decir considerarlas en sí mismas, fijarlas, establecerlas y determinarlas. Nosotros sólo las consideramos unas en relación con otras»...$^{38}$

Sobre esto mismo, y a modo de complemento, resulta especialmente relevante la entrada 813, donde Berkeley señala lo siguiente: «G Estoy cierto de que hay un Dios aun cuando no lo perciba, no tenga intuición alguna de él. esto no es difícil si entendemos correctamente lo que se quiere decir por certeza». De aquí se recoge algo importante, a saber, que se puede tener certeza de algo (como lo es Dios o incluso la mente) sin percibir ese algo e incluso, en el caso de Dios, sin tener intuición alguna de ello. Esta información es complementada con la nota 740 , en donde se dice que «PM Debemos con la Masa situar la certeza en los sentidos». Si se toman las dos citas juntas, se añade a lo

dicho que se puede estar seguro de algo que no se percibe porque, aunque suene paradójico, la seguridad, evidencia o certeza de tal conocimiento la brindan justamente los sentidos. Luego de leer lo anterior probablemente surja en el lector la siguiente pregunta: ¿Cómo puedo tener certeza de algo no conocido por los sentidos y, sin embargo, ser éstos los que me brindan dicha certeza? Todo indica que en los $C F$ si se quiere conocer a la mente, que -reitero-no es una idea, habrá que apelar en última instancia a la certeza de los sentidos.

Se puede concluir de los Comentarios, teniendo en cuenta que es una obra no publicada, que el conocimiento de la mente se da básicamente por medio de una intuición (antecedente de noción), estrechamente vinculada a una afec-

$35 \quad C F 563$, p. 89.

36 CF 847, p. 123.

37 CF 752, p. 113.

38 CF 540, p. 86. 
tación producida por diversos pensamientos y sensaciones. Esta concepción, aunque aún distante del conocimiento propiamente nocional, lo anuncia ya en su versión definitiva, plasmada en el famoso Tratado sobre los principios del conocimiento humano.

\section{SOBRE EL CONOCIMIENTO NOCIONAL}

Una vez planteado lo anterior es momento de entrar de lleno en el conocimiento nocional. Es a lo largo del Tratado de 1710, pero más aún en la segunda edición de $1734,{ }^{39}$ donde Berkeley desarrolla como tal la doctrina de la noción. En esta obra el término noción ya no es usado como sinónimo de intuición, sino que se le intenta dar un uso más riguroso y menos laxo con la intención de hacer de él un concepto que refiera, lo más adecuadamente posible, al conocimiento de la mente o espíritu. ${ }^{40}$ Como he dicho, la noción no se restringe a la mente sino que refiere o tiene por objeto «ciertas operaciones mentales, relaciones, otras mentes y Dios»; ${ }^{41}$ elementos que comparten el hecho de ser activos y de no poder ser conocidos como ideas, sino mediante actos u operaciones mentales. Se trata entonces de un asunto epistémico pero también de uno lingüístico, pues con el concepto de noción se busca delimitar, para asir intelectual y lingüísticamente, lo propio de una mente, es decir, su actividad y con ello su carácter cambiante, operacional y procesal.

En la obra publicada 'noción' ya no se reduce a intuición ni tampoco se le concibe como idea, por ser ésta pasiva e inerte. Más bien se entiende como una especie de «imagen pensante activa», como se indica en los Diálogos, pues de tal imagen no puede tenerse una idea sino precisamente una mera noción: «Tengo en mí mismo - dice Berkeley- no ya una idea inactiva, sino una especie de imagen pensante activa de la Deidad». ${ }^{42}$ Aunque la imagen pensante activa se centra en Dios es interesante retomarla porque, en última instancia, se refiere al conocimiento de una mente o espíritu (la divina), y en ese sentido ayuda a entender que la noción es un tipo de aproximación con-

39 En la segunda edición de los Principios (1734) Berkeley añadió líneas enteras para precisar la doctrina de la noción, lo que demuestra que con los años la cuestión resultó cada vez más relevante para él. Por eso es necesario contrastar cuidadosamente las dos ediciones ( $1710 \mathrm{y}$ 1734), tanto para conocer los cambios entre una y otra como para entender la disputa de la primera mitad del siglo veinte entre «desarrollistas» (Fraser, Johnston, Hicks, Metz, Wild y Bender) y «unitaristas» (Jessop y Luce), sobre si había o no unidad-continuidad en la doctrina berkeleyana.

Para ampliar la información sobre el contexto del término noción en Berkeley véase Park 1972, Apéndice I, pp. 155-157.

40 Davis indicó acertadamente que la noción no representa un tertium quid en el sistema filosófico berkeleyano (además de los espíritus e ideas). Davis 1959, p. 385.

41 Davis, op. cit., p. 384.

42 Dialogues, II, p. 232. 
ceptual cambiante y activa, totalmente distinta de una idea.

Cabe aclarar que el concepto de noción no es representativo en el sentido de que no representa, es decir, no hace presente a la mente, sea a través de imágenes o ideas (pasivas) de ella. Que dicho concepto no sea representativo conlleva que no puede no ser nocional, debido a que para Berkeley «no hay nada que pueda servir como representación de la mente. Las mentes son irrepresentables»». ${ }^{43} \mathrm{El}$ motivo por el que la mente no puede ser representada (que para algunos constituye el verdadero quid del acercamiento berkeleyano al problema de las otras mentes) es porque de serlo se convertiría en una idea, lo cual resultaría contradictorio e inadmisible para la filosofía del irlandés.

\section{IV.1 EL CONOCIMIENTO NOCIONAL DE LA PROPIA MENTE}

Para hablar sobre el conocimiento de la propia mente o yo, hay que considerar lo dicho respecto a que sólo se conocen ideas y a que la mente no es una idea. De esto resultan dos cosas: 1) que la mente no podrá ser conocida a la manera en que se conocen las ideas y 2) que si la mente es una palabra comprensible y por ello significativa (no siendo una idea), entonces sólo se podrá tener un indicio de ella o para ser más precisos una noción. Berkeley afirma en los Principios que «en un sentido amplio podemos decir que tenemos una idea o más bien una noción de espíritu, esto es, entendemos el significado de la palabra pues de otra manera no podríamos afirmar o negar nada de ella». ${ }^{44}$ Resulta entonces que si bien es cierto que se puede decir que se tiene idea de la mente es mejor usar la palabra noción, porque resulta más apropiada y precisa para distinguir, con la fuerza que amerita, términos distintos que refieren a cosas absolutamente diferentes (como son las ideas y los espíritus o mentes). ${ }^{45}$

Dicho lo anterior, puede darse un paso adelante en el conocimiento de la propia mente citando al propio filósofo:

es tal la naturaleza del espíritu o aquello que actúa que no puede ser percibido por sí mismo, sino sólo a través de los efectos que produce. [...] por lo que yo puedo ver las palabras voluntad, alma, espíritu no representan ideas diferentes o, en verdad, idea alguna, sino algo que es muy diferente de las ideas y que siendo un agente no puede ser semejante a, o representado por, ninguna idea. Aunque al mismo tiempo debe admitirse que tenemos alguna noción de alma, espíritu y de las operaciones de la mente, tales como querer, amar, odiar, en la medida en que

43 Roberts 2007, p. 81.

44 Principles, II, § 140, p. 105.

45 Ibid., § 142, p. 106. 
conocemos o entendemos el significado de esas palabras. ${ }^{46}$

Un primer aspecto a destacar de la cita es que confirma que la mente es una palabra significativa aunque no refiera a idea alguna; sin embargo, se añade que no sólo la mente sino también las palabras que refieren a actividad, como querer, amar u odiar, son significativas aunque no remitan a ninguna idea. Esto deja claro que aunque no se tenga idea de lo activo, como es la mente y sus diversas operaciones, no por eso (lo activo) deja de ser comprensible, lo que refuerza no sólo la validez sino hasta la necesidad del conocimiento nocional referido por Berkeley.

Otro aspecto relevante de la nota es que señala que a la mente se le percibe (conoce) por los efectos que produce. Surge inmediatamente la interrogante sobre cuáles son esos efectos, lo que lleva a retomar la pregunta formulada al final del apartado anterior, sobre los Comentarios Filosóficos, en relación a cómo puede ser que los sentidos den certeza de algo no conocido por los sentidos. La respuesta a estas interrogantes es que los efectos de la mente son sus ideas, lo que significa que el conocimiento de la propia mente se da gracias a las ideas que uno percibe en sí mismo; por eso se afirma que la noción de alma se adquiere a partir de uno mismo, ya que «lo que yo soy, lo que designo con el término yo, es lo mismo que lo referido por alma o sustancia espiritual». ${ }^{47}$ Esta noción de lo que yo soy, así como de la propia existencia, se comprende «por un sentimiento interior o reflexión, y la de los otros espíritus por la razón». ${ }^{48} \mathrm{Si}$ el alma o mente es lo mismo que lo referido por la palabra yo, entonces se hace patente que el conocimiento de la propia mente se da de forma inmediata, pues comprender el yo, es decir, las ideas producidas por uno mismo, es algo que no requiere de un aprendizaje prolongado y riguroso; por el contrario, es algo que se interioriza (de ahí el «sentimiento interior») de forma rápida e intuitiva, es decir, prácticamente inmediata, tal y como el filósofo reconoce en sus Diálogos al decir que «sé lo que quiero decir por los términos yo y yo mismo, y sé esto inmediata o intuitivamente, aunque no lo perciba como percibo un triángulo, un color o un sonido». ${ }^{49}$

Para aclarar un poco más el conocimiento de la propia mente considero importante subrayar la disyunción hecha por Berkeley (el «o» de la cita), entre sentimiento interior y reflexión. Disociando ambos elementos, el sentimiento interior serviría para acceder inmediatamente al yo, mientras que la reflexión lo haría para intentar descubrir qué es ese yo; la consecuencia de tal reflexión sería que la mente es, entre otras cosas, un algo que «piensa, quiere y percibe»

46 Ibid., § 27, p. 52.

47 Ibid., § 139, pp. 104-105.

48 Ibid., § 89, pp. 79-80.

49 Dialogues, II, p. 231. 
(§ 138).

De lo dicho hasta aquí se concluyen tres cosas respecto al conocimiento nocional de la propia mente:

1) que tal conocimiento es inmediato, en el sentido de que no hace falta un aprendizaje lento, pausado y riguroso para acceder al yo;

2) que no es ideacional, porque a la propia mente no se le conoce como idea sino mediante ellas;

3) que dicho conocimiento debe distinguirse, por ser diferente, del acceso nocional a otras mentes finitas y a Dios.

\section{IV.2 EL CONOCIMIENTO NOCIONAL DE LAS OTRAS MENTES}

Una vez expuesta la manera en que uno mismo se conoce (en tanto mente, espíritu, alma o yo), toca el turno de hablar sobre cómo se conocen las otras mentes. Si Berkeley ha dicho al respecto que las otras mentes son conocidas a través de la razón, implícitamente está diciendo que su conocimiento no es inmediato sino más bien mediato, pues un proceso cognoscitivo que requiere del ejercicio de la razón no se da ipso facto. Esto tiene que ver con lo dicho anteriormente sobre que una mente se conoce gracias a los efectos que produce, pues si los efectos originados por la propia mente son las ideas que surgen del pensar, querer y actuar, esto mismo se podrá aplicar a las otras mentes porque, en tanto mentes, son seres de naturaleza semejante a la de uno. Hay en esto una importante diferencia, a saber, que mientras las ideas de la propia mente se conocen inmediatamente las producidas por otras mentes no, ya que son efectos - como se ha dicho- de mentes distintas a la de uno. Esto es lo que hace posible sostener que si bien es cierto que ninguna idea o colección de ideas es una mente, sí es cierto que esto (una idea o una colección de ideas) resulta ser un signo o indicio de que hay otro ser volitivo, es decir, otra mente, además del mío, por eso «cada idea es una muestra de actividad, cada episodio de pasividad es un signo de actividad» $\gg{ }^{50}$ El propio Berkeley señala esto en su Alcifrón, al decir que «el ser de las cosas imperceptibles para el sentido puede ser deducido de efectos y signos o muestras sensibles» ${ }^{51}$ Esto mismo se encuentra antes en los Principios, donde se afirma:

No podemos conocer la existencia de otros espíritus más que por sus operaciones

50 Roberts, op. cit., pp. 76-77. Roberts sostiene que como los espíritus no pueden ser representados por ideas éstas se convierten en instrumentos (mediante los cuales aquéllos ejercen su voluntad) que pueden ser usados como signos para comunicarse con otros espíritus. Por eso la respuesta al problema de las otras mentes consiste en buscar signos para usarlos como señales, pues acorde a la metafísica berkeleyana la mera presencia de una idea es un signo de una mente distinta de la mía. Véase Roberts, op. cit., pp. 75-76.

51 Alciphron, III; iv, 4, p. 145. 
o por las ideas que producen en nosotros. Percibo diversos movimientos, cambios y combinaciones de ideas que me informan que existen ciertos agentes particulares, semejantes a mí mismo, que los acompañan y concurren a su producción. De ahí que el conocimiento que tengo de los otros espíritus no es inmediato, como lo es el conocimiento de mis ideas, sino que depende de la intervención de las ideas que yo refiero a agentes o espíritus distintos de mí mismo, como efectos o signos concomitantes. ${ }^{52}$

Por lo tanto, si la manera de conocer otras mentes es a través de los efectos que producen, cualesquiera que éstos sean, entonces el conocimiento nocional de aquéllas es de hecho indirecto, es decir, inferencial ${ }^{53}$ y por eso no es inmediato como el de la propia mente. Gracias a que se perciben diversos tipos de ideas, que van desde movimientos corporales (de ahí que «al afectar a otras personas la voluntad del hombre no tiene otro objeto que el simple movimiento de los miembros de su cuerpo» ${ }^{54}$ ) hasta sonidos, se puede colegir o inferir, mediante un acto de la razón, que hay algo que actúa, quiere y percibe de manera semejante a como lo hace uno, lo que conlleva que ese algo es de la misma naturaleza que la de uno pero, a la vez, en tanto que es otro, es distinto de uno mismo.

Un elemento importante a considerar para complementar lo dicho es el acto de hablar, directamente relacionado con el hecho de que para Berkeley la verdadera naturaleza del lenguaje está constituida por «la articulación, combinación, variedad, abundancia, uso general y extensivo y fácil aplicación de signos» ${ }^{55} \mathrm{El}$ acto de hablar, como prueba para demostrar la existencia de otras mentes y el acceso nocional a las mismas, se plantea en el cuarto diálogo del Alcifrón; allí se lee: «nada me convencerá más de la existencia de otra persona que su acto de hablarme. El escucharte hablar es, en estricta y filosófica verdad, la mejor prueba para mí de tu existencia». ${ }^{56}$

El argumento del habla es importante para el conocimiento nocional, debido a que sólo una mente (finita o infinita) es capaz de mostrarse a través de un conjunto coherente de enunciados que expresan lo que piensa o siente, por eso enfrentarse con un discurso es la principal evidencia de que se está tratando con una mente distinta a la propia. Hay que decir que lo peculiar del discurso es que las ideas (palabras-sonidos-signos) que lo conforman «admiten un cierto tipo de tratamiento por parte de un espíritu. Las ideas así organizadas

52 Principles, II, § 145, p. 107.

53 Park, op. cit., p. 64.

54 Principles, II, §147, p. 108.

55 Alciphron, III; iv, 12, p. 157.

56 Ibid.; iv, 6, p. 148. 
son interpretables». ${ }^{57}$ Según Roberts, esto pone de relieve dos cosas: 1) que la mente actúa sobre las cosas sensibles de manera distinta a como las organiza para un discurso; en el primer caso simplemente las usa para manipularlas, mientras que en el segundo se sirve de ellas para organizarlas en un discurso hablado o escrito con el fin de que otra mente actúe, y 2) la importante cualidad de la mente de poder 'interpretar', es decir, de ser un «agente interpretativo» que puede distinguir entre las diversas colecciones de ideas. Precisamente la manera en que las ideas son manipuladas en un discurso para conseguir un fin racional, revela que detrás de ellas hay una mente o, dicho de otra manera, un imperceptible «principio de pensamiento y acción» (Alciphron; iv, 7) responsable de organizarlas y tratarlas como instrumentos para operar la propia voluntad, gracias a lo cual es posible alcanzar la comunicación con otras mentes porque las ideas pasan de ser objetos lingüísticos a ser signos interpretables. La comunicación, por tanto, requiere estar preparado para la interacción, por eso «a través de nuestra habilidad para responder apropiadamente a los signos usados como señales resolvemos el 'problema de las otras mentes', ya que ser capaces de comunicar requiere de la habilidad para interpretar». ${ }^{58}$

Para esclarecer un poco más el asunto me serviré, a modo de ejemplo, de los autómatas creados por Vaucançon en la Francia del siglo XVIII (para usar un caso de la época y del contexto de Berkeley). Los autómatas del francés sorprendieron al público porque eran capaces de realizar una serie de acciones complejas propias de ciertos seres vivos, como tocar un tambor, una flauta o digerir. Frente a tales acciones seguramente hubo personas que se preguntaron, ¿hay detrás de tales autómatas una mente actuante (berkeleyana)? Pese a que Berkeley no profundizó demasiado en el conocimiento nocional, el ejemplo del autómata podría servir para aclarar ciertas cosas. De un autómata como los de Vaucançon, esto es, de un ser que actúa, responde y/o reacciona de forma programada, no se colegiría una mente actuante detrás de él. Lo anterior porque el irlandés no se limita a considerar acciones o pensamientos particulares, que sí podrían tener los autómatas, sino que más bien toma en cuenta tipos de acciones o pensamientos que, pese a sus diferencias, como se dan entre personas de diferentes naciones y distintas épocas, llevan a pensar mediante una inferencia basada en la semejanza con uno mismo que hay una mente detrás de las ideas percibidas. Los autómatas de Vaucançon, como podrían ser otros cualesquiera, eran capaces de realizar acciones específicas, como el pato haciendo la digestión, pero no de imitar la enorme gama de acciones, reacciones, estímulos o pensamientos característicos de una mente o espíritu propiamente dicho.

57 Roberts, op. cit., p. 78.

58 Ibid., p. 85. 
Puede concluirse de lo dicho que es por los muchos efectos (ideas) percibidos como se colige indirectamente la existencia de otra mente, pero debido a que esos efectos denotan un conjunto de operaciones y acciones coherentes, cuya actividad y cambio son constantes $-\mathrm{y}$ por ende inasibles al no poder fijarse y aprehenderse-, no se puede tener una idea de esa mente sino solamente una noción o, en otras palabras, un conocimiento nocional. ${ }^{59}$

\section{CONCLUSIÓN}

En este trabajo se expuso y analizó parte de la doctrina berkeleyana de la noción, la que representa el intento por parte del irlandés de acercarse conceptualmente a uno de los elementos centrales de su inmaterialismo filosófico: las mentes o espíritus.

Berkeley fue consciente desde joven, en la época de los Comentarios, que al no ser la mente una idea ni tampoco ser pasiva como las ideas resultaba un elemento difícil de explicar; más aún porque su propia actividad (cualidad determinante suya), que hacía que siempre fuera actuante en el sentido de que siempre producía ideas, generaba que resultara irrepresentable y prácticamente inconcebible. Para enfrentarse al problema de cómo conocer algo de lo que no se puede formar una idea se sirvió del término noción, con el propósito de, a partir de él, desarrollar un concepto para la mente o -dicho en otras palabras- para aquello que por su propia actividad no puede concebirse a la manera de una silla, un árbol o un cuerpo cualquiera. Por otro lado, pero en relación a esto, la doctrina del conocimiento nocional también es el intento berkeleyano de apalabrar correctamente a las mentes o espíritus para hacerlos más inteligibles. Se trata entonces de una propuesta filosófica compleja y poco conocida, pero lo bastante original y novedosa como para obligar a los estudiosos de la filosofía a acercarse a ella; precisamente este artículo pretendió, entre otras cosas, analizarla para poder discutirla y con ello valorarla en su justa medida.

\section{REFERENCIAS BIBLIOGRÁFICAS}

BERKELEY, G. 1948-1957: The Works of George Berkeley, Bishop of Cloyne, 9 vols. London: Nelson \& Sons Ltd.

, 1989: Comentarios Filosóficos. Introducción manuscrita a los Principios del conocimiento humano. Correspondencia con Johnson. México: IIF's-UNAM.

BENÍTEZ, L. 1986: «El espíritu como principio activo en Berkeley», Análisis Filosófico VI, 1, pp. 23-34.

59 Para conocer (nocionalmente) a la mente infinita o Dios Berkeley se sirvió en el Alcifrón de la analogía. Cfr. Alciphron, III; iv, 19-25, p. 166 ss. 
BETTCHER, T. M. 2008: Berkeley: A Guide for the Perplexed. London: Continuum.

DAVIS, J. W. 1959: «Berkeley's Doctrine of the Notion», The Review of Metaphysics 12, 3, pp. 378-389.

FLAGE, D. E. 1985: «Berkeley's Notions», Philosophy and Phenomenological Research 45, 3, pp. 407-425.

GREENBERG, A. R. 1978: «Reid, Berkeley, and Notional Knowledge», The Monist 61, 2, pp. 271-282.

HERRERA, A. 1986: «La noción de existencia en la ontología de Berkeley», Análisis Filosófico VI, 1, pp. 13-22.

KINGSTON, F. T. 1992: The metaphysics of George Berkeley, 1685-1753: Irish philosopher. Lewiston, N.Y.: The Edwin Mellen Press.

LOCKE, J. 1979: An Essay Concerning Human Understanding. New York: Oxford University Press.

MUEHLMANN, R. G. 1995: "The Substance of Berkeley's Philosophy», en: MUEHLMANN R. G. (comp.), Berkeley's Metaphysics: Structural, Interpretive, and Critical Essays. Pennsylvania: The Pennsylvania State University, pp. 89105.

NOLS, C. 2011:Zeichenhaften Wirklichkeit. Realitätals Ausdruck der kommunikativen Präsenz Gottes in der Theologie George Berkeleys. Tübingen: Mohr Siebeck.

PARK, D. 1972: Complementary Notions. A Critical Study of Berkeley's Theory of Concepts. The Hague: Martinus Nijhoff.

ROBERTS, J. A. 2007: A Metaphysics for the Mob. The Philosophy of George Berkeley. New York: Oxford University Press.

ROBLES J. A. 1990: Estudios berkeleyanos. México: IIF's-UNAM.

, 1984: «Génesis de la noción de sustancia espiritual en la filosofía de George Berkeley I», Dianoia 30, 30, pp. 67-87.

, 1986: «Génesis de la noción de sustancia espiritual en la filosofía de Berkeley II», Contextos IV, 7, pp. 43-54.

Alberto Luis LóPez es investigador postdoctoral en la Universidad de Québec en Trois-Rivières (Canadá).

Líneas de Investigación:

Berkeley, Locke, Filosofía Moderna, Filosofía novohispana y mexicana, Filosofía de la Ilustración y Postcolonialismo en México

Publicaciones recientes:

(2016): «El papel de los milagros en la filosofía de George Berkeley», Velázquez, A. (ed.), Episodios filosóficos del platonismo: ecos y tensiones. México: Torres Asociados - FES Acatlán (UNAM), pp. 333-355. 
(2016): Reseña: Sébastien Charles (ed.), Berkeley revisited: Moral, Social and Political Philosophy. International Philosophical Quarterly 56 (4), 224, pp. 10-12.

Correo electrónico: alberto.luislopez@yahoo.com 